\title{
MIELOGRAFIA DE CÃES SADIOS COM O MEIO DE CONTRASTE IOVERSOL. RESULTADOS LIQUÓRICOS E ANATOMO-HISTOPATOLÓGICOS ${ }^{1}$
}

\author{
MYELOGRAPHY IN NORMAL DOGS WITH IOVERSOL CONTRAST MEDIUM. \\ CEREBROSPINAL FLUID AND ANATOMOHISTOPATHOLOGICAL RESULTS
}

\section{Luciana Virgínia Costa Sarmento ${ }^{2}$ Eduardo Alberto Tudury ${ }^{3}$ Miriam Nogueira Teixeira $^{3}$ Frederico Celso Lyra Maia ${ }^{4}$ Éricka Rejane Correia Albuquerque ${ }^{5}$ \\ Patrícia Karla de Luna Magalhães ${ }^{6}$}

RESUMO

O meio de contraste ioversol $240 \mathrm{mg}$ de iodo(I) por $\mathrm{ml}$ foi administrado na dose de $0,5 \mathrm{ml} / \mathrm{kg}$ de peso por via intracisternal em 30 cães sadios, com o objetivo de verificar as possíveis alterações liquóricas e histopatológicas geradas pelo mesmo. Foram realizadas no líquor, análises físicas, contagens total e diferencial de leucócitos e determinação da concentração total de proteínas. A análise do líquor pós-mielográfica revelou aumento no número de leucócitos totais em três animais e da concentração de proteína em quatro. Alterações histopatológicas foram observadas em dois deles: infiltrado de células inflamatórias mononucleares na fissura ventral e no canal central da medula espinhal e infiltrado discreto de células inflamatórias mononucleares no canal central da medula espinhal, respectivamente. Concluiu-se que a mielografia com o meio de contraste ioversol $240 \mathrm{mg} \mathrm{I} / \mathrm{m} \ell$ pode causar alterações citológicas e na concentração de proteínas no líquor, e histopatológicas, porém discretas, durante o período estudado.

Palavras-chave: diagnóstico neurológico, coluna espinhal, cães.

\section{SUMMARY}

Ioversol contrast agent, at a concentration of $240 \mathrm{mg}$ of iodine/ml, was administered via intrathecal routes to 30 normal dogs at a dose of $0.5 \mathrm{ml} / \mathrm{kg}$ weight to determine possible cerebrospinal fluid and histopathological changes. Physical analysis, total and differential white cell counts and quantitative protein determination of the cerebrospinal fluid were done. Cerebrospinal fluid analysis revealed increase in the total white cell count in three animals, and protein in four animals of different groups post-myelography. Histopathological changes were seen in spinal cords of two dogs: mononuclear infiltrate in the ventral fissure and in the central canal, and mononuclear infiltrate in the central canal, respectively. Myelography with

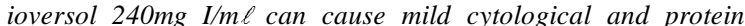
alterations, and histopathological changes under the experimental conditions.

Key words: myelography, ioversol, dogs.

\section{INTRODUÇÃO}

Desde a década de 20, quando a técnica mielográfica começou a ser realizada, os meios de contraste têm evoluído no sentido de promover baixa toxicidade. Sabe-se que os contrastes mais antigos

\footnotetext{
${ }^{1}$ Projeto financiado pela FACEPE, Humana Produtos Hospitalares, Coopers Brasil Ltda., Laboratórios Konig S.A. e Bayer do Brasil S.A.

${ }^{2}$ Médico Veterinário Autônomo, Mestre. Rua Pedro Antônio da Silva, 37, Piedade, 54400-400, Jaboatão dos Guararapes, Pe. E-mail: lvcsarmento@bol.com.br. Autor para correspondência.

${ }^{3}$ Médico Veterinário, Doutor, Professor Adjunto, Departamento de Medicina Veterinária(DMV), Universidade Federal Rural de Pernambuco(UFRPE).

${ }^{4}$ Médico Veterinário, Mestre, Professor Adjunto, DMV, UFRPE.

${ }^{5}$ Médico Veterinário Autônomo.

${ }^{6}$ Acadêmico de Medicina Veterinária, bolsista PIBIC/CNPq.
} 
como o methiodal sódico (RADBERG \& WENNBERG, 1973) e o etil iodofenilundecilato causavam aracnoidites com reação inflamatória das meninges e medula. $\mathrm{O}$ etil iodofenilundecilato, utilizado inicialmente na década de 40, provocava aumento severo de células totais no líquor e teste de Pandy (globulinas) positivo nos indivíduos estudados (WILSON et al., 1976). Esses autores observaram também, alterações histológicas das meninges com infiltrados de linfócitos, monócitos e células plasmáticas nos espaços subdural e subaracnóide. $\mathrm{O}$ contraste de meio coloidal thoratrast causava infiltrados principalmente de macrófagos e linfócitos (TAYLOR, 1958).

Os meios de contraste mais utilizados atualmente nas medicinas humana e veterinária para mielografia são o iohexol e o iopamidol. São produtos hidrossolúveis, não iônicos, e comprovadamente eficazes para diagnóstico, mas ainda associados a leptomeningites brandas (WIDMER, 1989). Nos últimos anos tem-se pesquisado o meio de contraste ioversol na realização de mielografias em humanos. Recentemente, o seu uso tem se estendido à medicina veterinária na concentração de $320 \mathrm{mg}$ de iodo(I) por $\mathrm{ml}$, apresentando mínimas reações adversas, quando utilizado em cães. Entretanto, foram observados no líquor aumentos de leucócitos (32 leucócitos $/ \mathrm{mm}^{3}$ ) e de proteína $(182 \mathrm{mg} / \mathrm{d} \ell$ ), com predomínio de linfócitos $(72 \%)$ sobre os segmentados $(28 \%)$ no quarto dias pós-mielografia (TUDURY et al., 1997). Administrando ioversol na concentração de $430 \mathrm{mg} \mathrm{I} / \mathrm{m} \ell$, pela via intracisternal a ratos, em doses entre 0,93 a $2,79 \mathrm{~m} \ell / \mathrm{kg}$ de peso, foi verificada menor toxicidade que a dos contrastes iohexol e iopamidol (RALSTON et al., 1989). Os mesmos autores administraram-no pela via intracisternal em cães anestesiados com tiopental sódico, nas doses de 0,37 e $0,56 \mathrm{~m} \ell / \mathrm{kg}$, e não foram constatadas anormalidades macroscópicas à necropsia 14 dias pós-injeção. Na concentração de $240 \mathrm{mg} \mathrm{I} / \mathrm{m} \ell$ é indicado para mielografias, mas tem sido pouco estudado no que concerne a seus efeitos sobre o líquido céfalo-raquidiano (LCR), as meninges e a medula espinhal.

Objetivou-se com este estudo determinar a neurotoxicidade do meio de contraste ioversol $240 \mathrm{mg} \mathrm{I} / \mathrm{m} \ell$ injetado na cisterna cerebelomedular para realização de mielografias de cães sadios, e se verificam as alterações liquóricas e histopatológicas geradas pelo mesmo.

\section{MATERIAL E MÉTODOS}

O experimento foi realizado nas instalações do Hospital Veterinário do Departamento de Medicina Veterinária da Universidade Federal Rural de Pernambuco. Foram utilizados 30 cães adultos, clinicamente sadios, sem distinção de raça e de sexo, com peso variando entre 9 e $12 \mathrm{~kg}$, selecionados no Centro de Vigilância Animal do Recife. Os cães foram vacinados com vacina sêxtupla $^{\mathrm{a}}$ por via subcutânea em dose única $\mathrm{e}$ vermifugados com produto oral à base de pamoato de pirantel e praziquantel ${ }^{\mathrm{b}}$. A sua alimentação consistiu de ração comercial e água "ad libitum".

Os animais foram separados em três grupos de 10 indivíduos (grupos I, II e III), de acordo com os dias da coleta do LCR (pré e pósmielografia), sendo esses de 0 e 7,0 e 14 e 0 e 28 dias para os três grupos respectivamente. Por meio das análises do dia 0 , foram determinados os parâmetros de normalidade liquórica considerandose o método utilizado. Foi utilizado o diazepam ${ }^{\mathrm{c}}$ a $0,5 \%$ na dose de $1 \mathrm{mg} / \mathrm{kg}$ e após cinco minutos tiopental sódico a $2,5 \%$ na dose de $12,5 \mathrm{mg} / \mathrm{kg}$, ambos por via intravenosa. Foram realizadas tricotomia e anti-sepsia com álcool iodado da região crânio-cervical dorsal e em seguida os cães foram entubados com sonda oro-traqueal apropriada.

O líquor foi coletado por gotejamento da cisterna cerebelomedular, depositando-o em tubos de vidro estéreis, sendo enviados imediatamente ao Laboratório de Patologia Clínica desta mesma instituição para estudo. Foram realizadas análises físicas, contagens total e diferencial de leucócitos, e concentração total de proteína.

A contagem total de leucócitos foi realizada de acordo com o método descrito por WRIGHT (1978). A contagem diferencial de leucócitos foi feita pelo método da sedimentação descrito por STEINBERG \& VANDEVELDE (1974). A câmara de sedimentação foi confeccionada a partir de um tubo de seringa plástica, cortado e acoplado em lâmina de microscopia com cola de silicone $e^{\mathrm{e}}$. O LCR foi conservado misturando-o na proporção de 1:1 com soro sanguíneo canino no próprio tubo de seringa. A lâmina foi corada com May-Grumwald e Giemsa.

A análise da concentração total de proteína foi realizada pelo método do sulfossalicílico modificado utilizando uma solução com ácido sulfossalicílico a $3 \%$ e padrões de proteína com concentrações de $20 \mathrm{mg} / \mathrm{d} \ell, 40 \mathrm{mg} / \mathrm{d} \ell$ e $80 \mathrm{mg} / \mathrm{d} \ell$. A leitura foi realizada em fotocolorímetro, em absorvância, com filtro 420.

A mesma agulha colocada na cisterna cerebelomedular foi utilizada para a coleta do LCR, e para injetar lentamente o ioversol $240 \mathrm{mg} \mathrm{I} / \mathrm{m} \ell^{\mathrm{g}}$, na dose de $0,5 \mathrm{~m} \ell / \mathrm{kg}$ de peso, no espaço subaracnóide. Uma radiografia cervical foi obtida aos cinco 
minutos para verificar a correta administração do contraste.

A eutanásia foi realizada aos sete dias para o primeiro grupo, 14 dias para o segundo e 28 dias para o terceiro. Primeiro os animais foram anestesiados com cloridrato de xilazina ${ }^{\mathrm{h}}$ na dose de $1 \mathrm{mg} / \mathrm{kg}$ e cloridrato de ketamina ${ }^{\mathrm{i}}$ na dose de $8 \mathrm{mg} / \mathrm{kg}$, com posterior injeção de cloreto de potássio a $10 \%$, todos por via intravenosa. No dia da eutanásia, imediatamente antes da administração do cloreto de potássio, o LCR foi novamente coletado, sendo efetuadas as mesmas análises citadas anteriormente. Os resultados das análises foram submetidos ao Teste $t$ de Student para amostras pareadas, com nível de significância de $95 \%$.

Os segmentos cervicais (C1-C7) das medulas espinhais foram coletados, analisados macroscopicamente e fixados em solução tamponada de formol a $10 \%$ até o seu processamento histológico. $\mathrm{O}$ processamento consistiu em desidratação, diafanização, impregnação e inclusão em parafina. Os cortes foram feitos em micrótomo com espessura de $4 \mu \mathrm{m}$ e em seguida montados em lâminas de microscopia e corados com hematoxilina e eosina. Foi feita a leitura em microscópio óptico à procura de lesões inflamatórias, degenerativas ou necróticas das meninges e medulas espinhais.

\section{RESULTADOS E DISCUSSÃO}

As características físicas do LCR (cor, turbidez e coagulação) apresentaram-se normais e inalteradas em todos os animais. As análises citológicas liquóricas nos períodos pré e pósmielografia, não demonstraram alterações compatíveis com lesões patológicas significativas, sugerindo baixa neurotoxicidade do ioversol, já citada por RALSTON et al. (1989). Pode-se observar, nas tabelas 1 e 2 as médias dos valores encontrados e seus respectivos desvios padrão. Os valores normais de contagem absoluta leucocitária citados por COOK \& DeNicola (1988), ChrisMAN (1992), BAILEY \& Vernau (1997) e MEINKOTH \& CRYSTAL (1998) $\quad(0 \quad$ a $\quad 8$ leucócitos $\left./ \mathrm{mm}^{3}\right), \quad$ não condizem com os valores encontrados nesta pesquisa antes da mielografia, que foram de 2 a 18 leucócitos $/ \mathrm{mm}^{3}$. $\mathrm{Na}$ análise pós-mielográfica da contagem absoluta de leucócitos (Tabela 1), apesar das elevações nas médias
Tabela 1 - Contagem total de leucócitos presentes no líquor dos 30 cães antes e após a administração do meio de contraste ioversol.

\begin{tabular}{lcc}
\hline \multirow{2}{*}{ Grupos (Dias) } & \multicolumn{2}{c}{ Leucócitos $/ \mathrm{mm}^{3}$} \\
& Pré-mielografia $\mathrm{x} \pm \mathrm{s}$ & Pós-mielografia $\mathrm{x} \pm \mathrm{s}$ \\
\hline I: 0-7 & $5,40 \pm 3,30$ & $5,90 \pm 3,54$ \\
II: $0-14$ & $6,40 \pm 5,14$ & $12,90 \pm 19,21$ \\
III: $0-28$ & $7,90 \pm 6,08$ & $19,20 \pm 20,97$ \\
\hline
\end{tabular}

*A análise estatística não evidenciou diferença significativa $(\mathrm{P} \geq 0,05)$

pós-mielográficas dos grupos II e III (14 e 28 dias), essas não foram estatisticamente significativas. Apenas um animal do grupo II e dois animais do grupo III, apresentando respectivamente 66, 56 e 59 leucócitos $/ \mathrm{mm}^{3}$, foram responsáveis por este aumento, decorrente provavelmente de efeitos irritativos meningeais do meio de contraste, conforme citado por FELDMAN (1989).

As análises pós-mielografia da diferenciação leucocitária (Tabela 2) demonstraram aumento dos linfócitos nos grupos I e II, e de monocitóides no grupo III, porém estatisticamente não significativo. Esse aumento não foi considerado de significado patológico, já que, além de ser discreto, a proporção das células manteve-se dentro da normalidade: 60 a $80 \%$ dos leucócitos totais compostos pelos linfócitos e 20 a $40 \%$ pelos monocitóides conforme descrito por DUNCAN et al.(1987).

Chrisman (1992) e MeInKoth \& CRYSTAL (1998) citam 10 a $25 \mathrm{mg} / \mathrm{d} \ell$ como valores normais para a concentração total de proteína liquórica cisternal, diferindo dos valores encontrados neste estudo nas análises pré-mielográfica (13$38 \mathrm{mg} / \mathrm{d} \ell$ ). Segundo CHRISMAN (1992), esses valores podem variar de laboratório para laboratório assim como pelo método utilizado. Os resultados das análises nos grupos I, II e III (Tabela 3), no período

Tabela 2 - Contagem relativa de linfócitos, monocitóides e neutrófilos presentes no líquor antes e após a administração do meio de contraste ioversol em cães.

\begin{tabular}{|c|c|c|c|c|c|c|}
\hline \multirow[t]{2}{*}{$\begin{array}{l}\text { Grupos } \\
\text { (Dias) }\end{array}$} & \multicolumn{3}{|c|}{$\begin{array}{c}\text { Pré-mielografia }(\%) \\
x \pm s\end{array}$} & \multicolumn{3}{|c|}{$\begin{array}{c}\text { Pós-mielografia (\%) } \\
x \pm s\end{array}$} \\
\hline & Linfócitos & Monocitóides & Neutrófilos & Linfócitos & Monocitóides & Neutrófilos \\
\hline I: $0-7$ & $74,38 \pm 6,65$ & $17,44 \pm 10,19$ & $8,16 \pm 9,92$ & $80,23 \pm 7,45$ & $17,70 \pm 4,46$ & $2,71 \pm 4,86$ \\
\hline II: $0-14$ & $72,88 \pm 9,97$ & $20,59 \pm 7,94$ & $5,95 \pm 2,90$ & $76,08 \pm 6,93$ & $20,10 \pm 6,80$ & $3,80 \pm 3,85$ \\
\hline III: $0-28$ & $73,62 \pm 6,51$ & $23,14 \pm 6,27$ & $3,22 \pm 2,79$ & $70,41 \pm 7,57$ & $26,05 \pm 7,17$ & $3,52 \pm 3,60$ \\
\hline
\end{tabular}

*A análise estatística não evidenciou diferença significativa $(\mathrm{P} \geq 0,05)$

Ciência Rural, v. 32, n. 3, 2002. 
pós-mielografia, evidenciaram elevações discretas e estatisticamente não significativas. No grupo I, três animais apresentaram respectivamente 50,4; 40,8 e $66 \mathrm{mg} / \mathrm{d} \ell$ e no grupo III apenas um animal apresentou $39,6 \mathrm{mg} / \mathrm{d} \ell$ de proteína liquórica, o que sugere discreta irritação das meninges. Os animais que apresentaram alterações citológicas não foram os mesmos que apresentaram alterações protéicas. Aumento do número de células do líquor (linfócitos, monocitóides ou neutrófilos) pode ser acompanhado ou não de aumento na concentração de proteína total e vice-versa (MEINKOTH \& CRYSTAL, 1998). Alterações citológicas e protéicas do LCR semelhantes àquelas aqui encontradas, já tinham sido citadas por TUDURY et al. (1997) em animais submetidos a mielografia com o ioversol, mas que após o procedimento não vieram a apresentar efeitos adversos neurológicos nem lesões histopatológicas.

$\mathrm{Na}$ análise macroscópica das medulas espinhais cervicais (C1-C7), foi observada a presença de sangue na porção cranial e abaixo das meninges em 13 das 30 medulas estudadas, sete do grupo I, uma do grupo II e cinco do grupo III. Esse achado foi associado à punção (MAYHEW \& BEAL, 1980; Coles, 1984; CoOK \& DeNicola, 1988) e também a extravasamentos sangüíneos citados por PALMER (1990) e Sullivan (1993), adquiridos do plexo vertebral interno quando as medulas foram separadas da cabeça por secção na junção atlantooccipital. Nos estudos histopatológicos constataramse hemorragias subdurais e subaracnóideas, confirmando os achados macroscópicos. Hemorragia também foi observada na substância cinzenta de duas medulas do grupo I, relacionando-se este fato à técnica de sua retirada do canal vertebral. As hemorragias encontradas não foram relacionadas ao meio de contraste, já que, conforme descrito por WELLER (1984), sete dias após uma hemorragia, as hemácias estariam ausentes devido à hemólise e remoção pelos macrófagos. Foi verificada congestão discreta nas substâncias branca e cinzenta, em 13 medulas, sendo cinco do grupo I, três do grupo II e cinco do grupo III, acreditando-se que tenham decorrido de efeitos depressores cardíacos e vasculares dos fármacos anestésicos e de eutanásia, conforme citados por JONES et al. (1977) e HALL \& Clarke (1983). Em uma medula do grupo II, foram observados infiltrados discretos de células inflamatórias mononucleares na fissura ventral e no canal central (Figura 1), e em outra medula do grupo III, infiltrados discretos de células inflamatórias
Tabela 3 - Concentrações totais de proteínas presentes no líquor antes e após a administração do meio de contraste ioversol em cães.

\begin{tabular}{lll}
\hline \multirow{2}{*}{$\begin{array}{l}\text { Grupos } \\
\text { Dias })\end{array}$} & \multicolumn{2}{c}{ Proteínas Totais $(\mathrm{mg} / \mathrm{d} \ell)$} \\
\cline { 2 - 3 } & Pré-mielografia $\mathrm{x} \pm \mathrm{s}$ & Pós-mielografia $\mathrm{x} \pm \mathrm{s}$ \\
\hline I: $0-7$ & $26,4 \pm 7,20$ & $33,40 \pm 15,57$ \\
II: $0-14$ & $21,10 \pm 3,35$ & $23,40 \pm 6,43$ \\
III: $0-28$ & $23,20 \pm 6,57$ & $28,90 \pm 7,00$ \\
\hline
\end{tabular}

* A análise estatística não evidenciou diferença significativa $(\mathrm{P} \geq 0,05)$

mononucleares no canal central (Figura 2). Sugerese que esses achados estejam relacionados com o meio de contraste, já que também foram observados por TAYLOR (1958) e WILSON et al. (1976) utilizando o thoratrast e etil iodofenilundecilato respectivamente. No entanto, não indicaram irritabilidade ou neurotoxicidade significativas tendo em conta serem discretos quando comparados com os achados relacionados a esses outros autores e considerando-se que somente dois de 30 animais vieram a exibir infiltrado de células inflamatórias. Atribui-se parte dessa inocuidade, também observada por TUDURY et al. (1997), à rápida eliminação do ioversol do espaço subaracnóide.

\section{CONCLUSÃO}

O meio de contraste ioversol 240mg I/m $\ell$, quando injetado na cisterna cerebelomedular para a realização de mielografias em cães, apresenta baixa

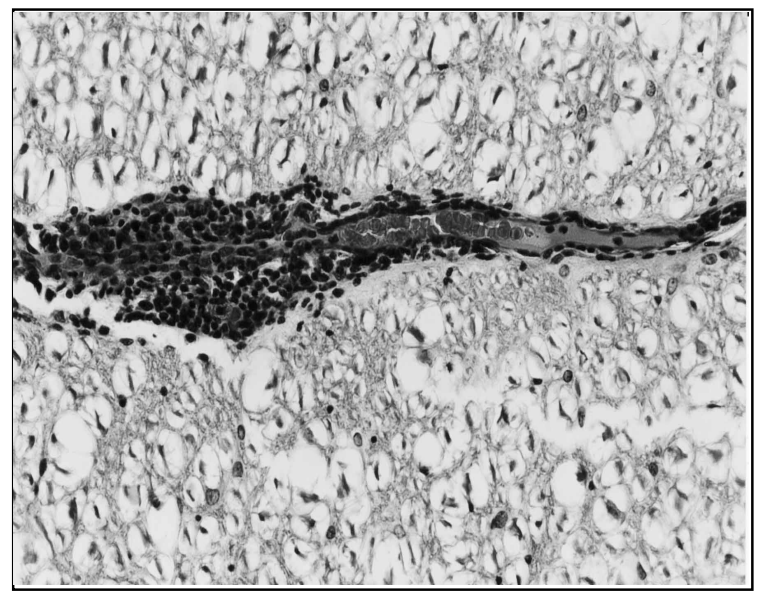

Figura 1 - Fotomicrografia da medula espinhal de cão do grupo II submetido à mielografia com o meio de contraste ioversol. Nota-se infiltrado de células inflamatórias mononucleares na fissura ventral e no canal central da medula espinhal. (Coloração Hematoxilina-Eosina, 342X). 


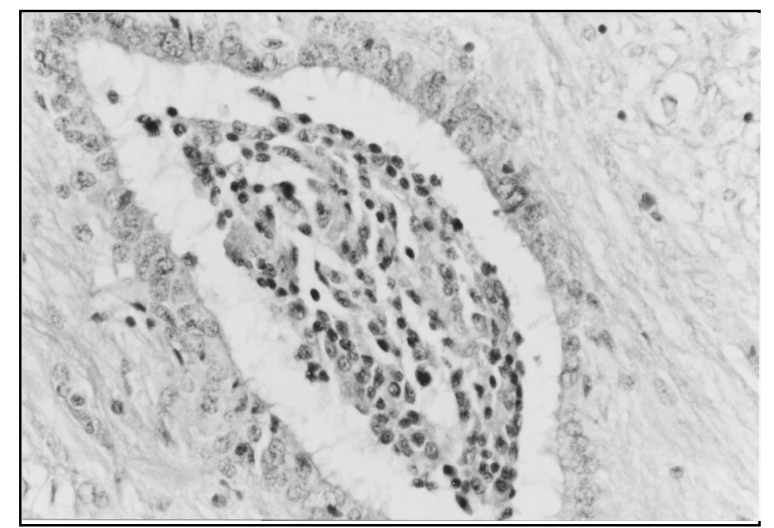

Figura 2 - Fotomicrografia da medula espinhal de cão do grupo III submetido à mielografia com o meio de contraste ioversol. Nota-se Infiltrado de células inflamatórias mononucleares no canal central da medula espinhal. (Coloração Hematoxilina-Eosina, 548X).

neurotoxicidade, sem elevar estatisticamente as contagens absoluta e diferencial dos leucócitos e os níveis de proteína total, evidenciando raras e discretas alterações histopatológicas das meninges e medula espinhal.

\section{FONTES DE AQUISIÇÃO}

a Tissuvax 6-Mallinckrodt Veterinary. Coopers Brasil Ltda. Campinas-SP

${ }^{\mathrm{b}}$ Drontal-Bayer do Brasil S.A. São Paulo-SP

c Diazepam-União Química Farmacêutica Nacional S.A. EmbuGuaçu-SP

d Tiopental-Cristália Produtos Químicos Farmacêuticos Ltda. Itapira-SP

${ }^{\mathrm{e}}$ Dow Corning do Brasil Ltda. Hortolândia-SP

${ }^{\mathrm{f}}$ Analyser 500s-Analyser Comércio Indústria Ltda. Mandaqui-SP

g Optiray®240-Mallinckrodt Medical Inc. Humana Produtos Hospitalares Ltda. Rio de Janeiro-RJ

${ }^{\text {h }}$ Kensol®- Laboratórios König S.A. São Paulo-SP

${ }^{\mathrm{i}}$ Vetanarcol@- Laboratórios König S.A. São Paulo-SP

\section{REFERÊNCIAS BIBLIOGRÁFICAS}

BAILEY, C.S., VERNAU, W. Cerebrospinal fluid. In: KANEKO, J.J., HARVEY, J.W., BRUSS, M.L. Clinical biochemistry of domestic animals. San Diego : Academic, 1997. Cap.27, p.785-827.

CHRISMAN, C.L. Cerebrospinal fluid analysis. Veterinary Clinics of North America: Small Animal Practice, v.22, n.4, p.781-809, 1992.

COLES, E. H. Patologia clínica veterinária. 3ed. Rio de Janeiro : Manole, 1984. Cap.15: Fluido cerebrospinal: p.367-381.

COOK, J.R., DENICOLA, D.B. Cerebrospinal fluid. Veterinary Clinics of North America: Small Animal Practice, v.18, n.3, p.475-499, 1988 .

DUNCAN, J.R., OLIVER, J.R., MAYHEW, I.G. Laboratory examinations. In: OLIVER, J.E., HOERLEIN, B.F., MAYHEW, I.G. Veterinary neurology. Philadelphia : Saunders, 1987. Cap. 3, p.57-64.

FELDMAN, B.F. Cerebrospinal fluid. In: KANEKO, J.J. Clinical biochemistry of domestic animals. 4.ed. San Diego : Academic, 1989. Cap. 27, p.835-865.

HALL, L.W., CLARKE, K.W. Veterinary anaesthesia. 8ed. London: Baillière Tindal, 1983. 417p.

JONES, A.B., BOOTH, N.H., Mc. DONALD, L.E. Veterinary pharmacology and therapeutics. 4 ed. Iowa : Iowa State University, 1977. 1380p.

MAYHEW, I.G., BEAL, C.R. Techniques of analysis of cerebrospinal fluid. Veterinary Clinics of North America: Small Animal Practice, v.10, n.1, p.155-176, 1980.

MEINKOTH, J.H., CRYSTAL, M.A. Cerebrospinal fluid analysis. In: COWELL, R.L, TYLER, R.D., JAMES, H.M. Diagnostic cytology and hematology of the dog and the cat. 2.ed. Saint Louis : Mosby, 1998. Cap.11, p.125-141.

PALMER, A.C. The use and principles of neuropathology for clinicians. Compendium on Continuing Education for the Practicing Veterinarian, v.1, n.1, p.48-58, 1990.

RADBERG, C., WENNBERG, E. Late sequelae following myelography with water-soluble contrast media. Acta Radiologica Diagnosis, v.14, n.5, p.507-512, 1973.

RALSTON, W.H., ROBBINS, M.S., COVENEY, J. R., $\boldsymbol{e}$ t al. Acute and subacute toxicity studies of ioversol in experimental animals. Investigative Radiology, v.24, n.1, p.2-9, 1989.

STEINBERG, S.A., VANDEVELDE, M. A comparative study of two methods of cytological evaluation of spinal fluid in domestic animals. Folia Veterinaria Latina, v.4, p.235-250, 1974.

SULLIVAN, N.D. The nervous system. In: JUBB, K.V.F., KENNEDY, P.C., PALMER, N. Pathology of domestic animals. 4ed. San Diego : Academic, 1993. Cap. 3, p.201338.

TAYLOR, D.C. The pathological effects of thorotrast mielography in the dog. Journal of Comparative Pathology and Therapeutics, v.68, p.213-219, 1958.

TUDURY, E.A., ARIAS, M.V.B., CAMARGO, P.L., et al. Meio de contraste ioversol em neuroradiologia canina. Ciência Rural, Santa Maria, v.27, n.4, p.1-5, 1997.

WELLER, R.O. Color atlas of neuropathology. New York: Oxford University, 1984. Cap.3: Cerebral vascular disease: p.22-32.

WIDMER, W. R. Iohexol and iopamidol: new contrast media for veterinary myelography. Journal of the American Veterinary Medical Association, v.194, n.12, p.1714-1716, 1989.

WILSON, J. M., BAHR, R. J., LEIPOLD, H. W., et al. Acute leptomeningeal reaction to the subarachnoid injection of ethyl iodophenylundecylate in dogs. Journal of the American Veterinary Medical Association, v.169, n.4, p.415-418, 1976.

WRIGHT, J.A. Evaluation of cerebrospinal fluid in the dog. Veterinary Record, v.103, p.48-51, 1978. 